\title{
Knowledge Acquisition in Nepalese Telecom Industry
}

\author{
Laxman Raj Kandel, M.Phil. \\ Lecturer \\ Nepal Commerce Campus, Faculty of Management, T.U.
}

\begin{abstract}
This research paper presents the Knowledge Management practice in Nepalese telecom sector. This study is based on cross section analysis of 85 observations for analyzing relationship between the knowledge management (KM) practices status in Nepalese telecom sector. The methodology used by Kohli (1993) and Daroch (2003) has been used for the research. Survey instruments were organized into one part and five factors. Spearman Rank Correlation, Analysis of variance (ANOVA), Cronbach's alpha etc. is used for data analysis. The valid response rate of $70 \%$ was found. Among the factors that designed for knowledge acquisition, information input- employee has less mean score and information input-financial has high mean score than the others factors. In case of Information input-competitors, Nepalese telecom industry analyzes the financial contribution of their products or services. Employees of Nepal telecom has rated higher mean value in the KM practices i.e. knowledge acquisition, which means Nepal telecom appeared good in KM practices than Ncell. There is a significant difference between Nepal telecom and Ncell in term of the knowledge acquisition. Nepal telecom has better KA (Knowledge Acquisition) practices. Correlation matrix was computed to assess the extent or degree of relationship in between the factors or the research variables.
\end{abstract}

Key words: Knowledge Management, Acquisition, information, employees, technology, competitors

\section{Introduction}

Now-a-days, knowledge management is a newly emerging interdisciplinary business model that is rooted in many disciplines, including business, economics, psychology, and information management (Rafeeq, Nizamuddin, Asma, Ahmed, \& Afsar, 2014). It is ultimate competitive advantage for today's firm. Knowledge management involves people, technology, and processes in an organization (Nonaka \& Takeuchi, 1995). According to Alavi and Leider (2001) said that knowledge is justified personal belief. It increases an individual's capacity to take effective action." Similarly, in one study, Sveiby (1997) suggested that knowledge is an intangible resource that exists within the mind of the individual.

In one study Polanyi (1964) argued that knowledge can be of two types such as explicit or tacit. In one hand, explicit knowledge is expressed in numbers and words that are easily shared formally and systematically in the form of data and manuals. Whereas Connell, Klein and Powell (2003) suggested that explicit knowledge is about knowing something. They reported tacit knowledge includes insights, intuition, and hunches. They are often built by experience and difficult to formalize and share. In this regards, this research is about knowledge acquisition in Nepalese telecom industry. 


\section{Statement of the Problem}

The knowledge management is implemented in public sector organizations more for providing services to the public rather than towards gaining financial profit. Consistent with Darroch (2003), knowledge management is presented in three parts: knowledge acquisition, knowledge dissemination and responsiveness to knowledge. On the basis of above discussion, the specific research problems towards which this study is directed are:

- What are the perceptions on the benefits, problems, responsibilities and technological aspects that are entailed in managing the knowledge in Telecom industry?

- What are the relationships between the KM practices in Nepalese Telecom industry?

- What are the disparities in the approaches of KM practices in Nepalese Telecom industry?

- What are the practices of knowledge acquisition in Telecom industry?

\section{Research questions}

These research questions are the basis of exploratory research design in the present study.

- What is the nature of KM practices in Nepalese Telecom sector?

- What are the current practices of knowledge acquisition in Nepalese Telecom sectors?

- What are the features of KM practices in Nepalese Telecom industry?

- Is there any significance differences in KM practices among the Telecom of private and government sector?

- What is the relationship between the KM practices in Nepalese Telecom sector?

\section{Research Objectives}

On the basis of above explanation, the major objectives of this study are as follows:

- To study knowledge management practices of Nepalese Telecom industry.

- To obtain comprehensive information on how knowledge is managed in Telecom sector organizations.

- To investigate and examine the relationship of KM practices of Nepalese Telecom sectors.

- To examine the opinions of employees of knowledge management of Nepalese Telecom organizations.

\section{Conceptual Framework}

This study examined the role of effective knowledge management of Nepalese Telecom sector in two ways. First, the study examines the perceptions and use of knowledge management in Telecom organizations. Second, this study will be proposed a positive relationship within the components of knowledge acquisitions. Consistent with Darroch (2003), knowledge management is presented in three parts: knowledge acquisition, knowledge dissemination and responsiveness to knowledge. For this research study the knowledge acquisition will considered as an independent variable. 
Figure 1: Conceptual Model

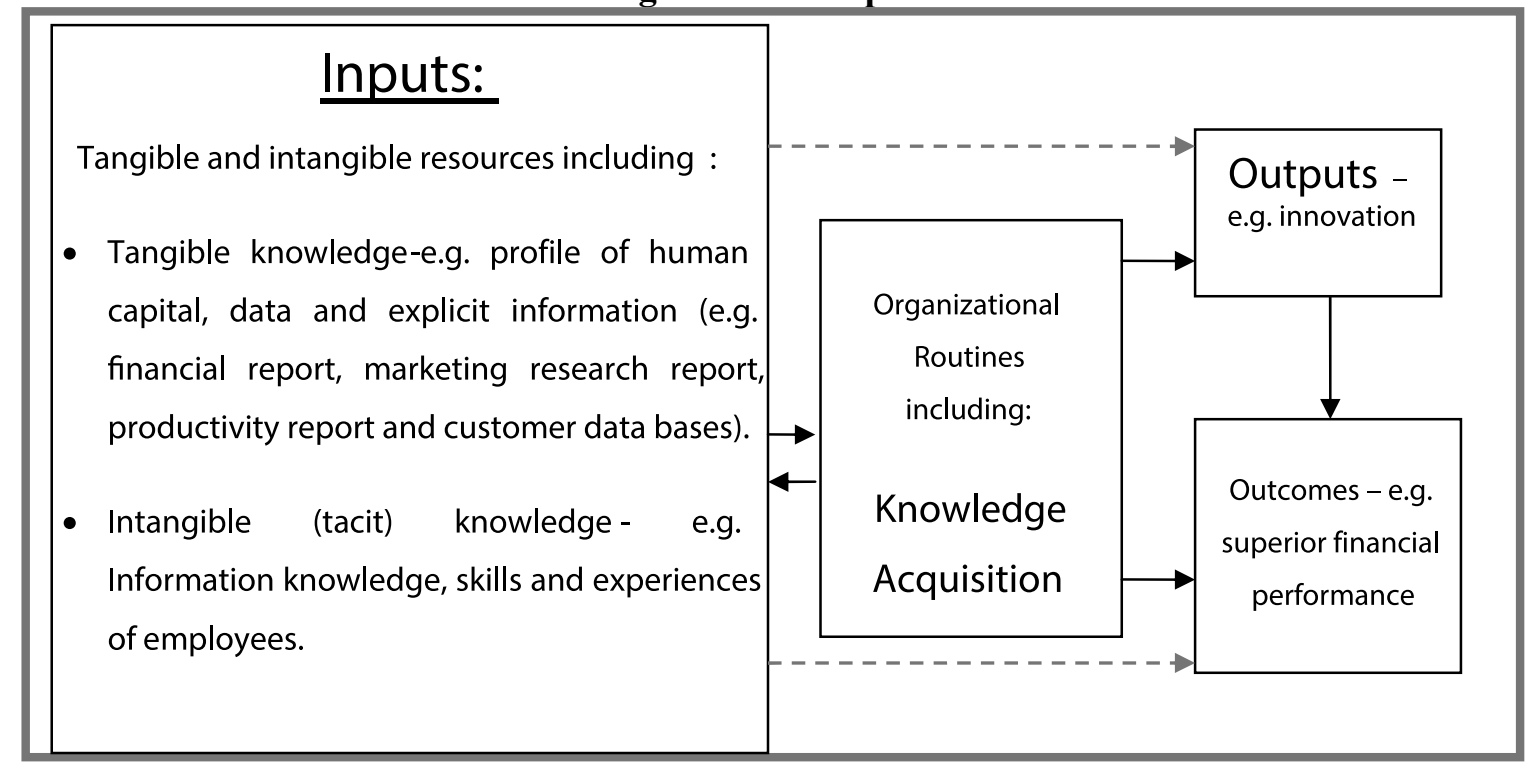

\section{Review of literature}

Now-a-days, knowledge management is paid increasingly more attention in business firms (Chase, 1997). There are different ways of generating and transferring knowledge across different levels (Nonaka \& Takeuchi, 1995). As Nonaka (1994) reported that knowledge management is the process of capturing a firm's knowledge and using it to foster innovation through a spiral of organizational learning of the firm.

Syed-Ikhsan and Rowland (2004) investigated and examined the availability of a knowledge management strategy in an empirical study in a public organization in Malaysia. They argued that perceptions on the benefits, problems, responsibilities and technological aspects that are entailed in managing knowledge in organizations. In another study, Liebowitz and Beckman (1998) investigated how knowledge management could build and nurture a knowledge sharing culture in a firm. Liebowitz and Beckman (1998) also found that knowledge sharing in government possesses some unique challenges in organizations. They discovered that government agencies are typically hierarchical and bureaucratic organizations that make difficult to share knowledge.

Wiig (2000) also made a comprehensive study on knowledge management in public administration. Wigg investigated how knowledge management could play important roles in public administration particularly in four main areas, which were (Wigg, 20002, p. 224). Al-Athari and Zairi (2001) have carried out another research project on knowledge management in both private and public sector organizations. Their study examined the actual situation on the availability of knowledge management systems (KMS) in 77 Kuwaiti organizations.

Liebowitz and Beckman (1998) have also conducted another study on knowledge management issues in public sector organizations. In their study, they investigated how knowledge management could build and nurture a knowledge sharing culture in an organization. In order to rate how well an organization is performing knowledge sharing activities. In a study, Liebowitz and Beckman (1998) found that the organization has a relatively better knowledge management environment and communication flows, but has poor organization facilitation and measurement. 
Table 1 List of some important Researches done in the

KM practices in public and private organization

\begin{tabular}{|l|l|l|}
\hline \multicolumn{1}{|c|}{ Km Practices } & \multicolumn{1}{c|}{ Empirical study } & \multicolumn{1}{c|}{ Results } \\
\hline Knowledge Acquisition & Cooper (1979) and LI(1998) & Positive \\
Acquiring market knowledge & Lynn et al. (2000) and Tang \\
Acquiring knowledge from employees. & Positive, Positive \\
Acquiring firms as a source of new ideas. & $\begin{array}{l}\text { (1999), Capon et al. (1992) } \\
\text { Capon et al. (1992) }\end{array}$ & Not significant. \\
\hline
\end{tabular}

\section{Research Design}

\section{Research Methodology}

This research is basically analytical and descriptive in nature which was undertaken by following the descriptive cum survey design to investigate and examine the availability of knowledge management practices in the telecom sectors organization of Nepal.

Numbers of literature were reviewed to identify the knowledge management practices. Survey data were collected from the multiple employees of respondent by using the structured set of questionnaire. The instrument is based on the Kohli-Jaworski market-orientation instrument (Kohli et al., 1993) that was developed to measure a firm's ability to acquire, disseminate and use market information.

\section{Population and Sample Size}

For this study all the telecom sector organizations including public and private, were considered as population and two organizations i.e. Nepal Telecom (Public) and Ncell (Private) were selected for sampling. This study was based on cross section analysis of 85 observations for analyzing relationship between the knowledge management (KM) practices status in Nepalese telecom sector.

\section{Nature and Sources of Data}

Basically primary data were used for the study and they were collected mainly from questionnaires. The respondents' job title included: General manager/director/CEO, assistant director, assistant manager, engineer, information system officer, assistant administration officer, technical officer, assistant information officer, legal officer, accountant and internal auditor.

\section{Method Analysis}

This current study more or less followed the methodology used by Kohli (1993) and Daroch (2003). In this study sample organizations were categorized into two groups according to private and public sector. The survey instruments were organized into one parts and sixteen factors (i) Knowledge acquisition.

Knowledge Management Practices and Measures: one observable components i.e. Knowledge Acquisition of the KM practices have been used to obtain the characteristics of KM practices. The characteristics of KM practices the knowledge acquisition is as follows:

- Knowledge Acquisition:- this is the constructed measure knowledge acquisition which is an index, based on five knowledge acquisition related questions from the employee survey (Information input- customer, competitors, financial, employee and technology).

\section{Distribution of Organization and respondents}

Following table shows the frequency distribution of the respondents for the type of organizations. 
Vol. 4, No. 1

Table 2 Frequency table of Respondents from NTC (Public) and NCELL (Private)

\begin{tabular}{|c|c|c|c|c|}
\hline Telecom industry & Frequency & Percent & Valid Percent & Cumulative percent \\
\hline $\begin{array}{l}\text { Nepal Telecom } \\
\text { Ncell }\end{array}$ & $\begin{array}{l}61 \\
24\end{array}$ & $\begin{array}{l}71.76 \\
28.24\end{array}$ & $\begin{array}{l}71.76 \\
28.24\end{array}$ & $\begin{array}{l}71.76 \\
100.0\end{array}$ \\
\hline Total & 85 & 100.0 & 100.0 & \\
\hline
\end{tabular}

The table 2 shows that there is major participation of Nepal Telecom having $71.76 \%$ of total respondents and 28.24 percentages from Ncell.

\section{Statistical Tools Used}

- $\quad$ Spearman Rank Correlation., Analysis of variance (ANOVA), Cronbach's alpha (Cronbach's , 1951)

\section{Data Collection Methods and processing}

In total 120 survey questionnaire were distributed with the valid response rate $70 \%$ which was adequate for the purpose of data analysis. The survey questionnaire were generated with the view to obtain self-reported attitude of respondents, $5=$ denotes strongly agree and $1=$ indicates strongly disagree.

\section{Analysis of Chronbach alpha (Reliability Test)}

Survey participants returned the 153 completed and filled questionnaire. The overall reliability of the variables is tested that constitutes the overall Cronbach's alpha value is 0.764 including 34 variables items.

Table 3 Chronbach alpha

\begin{tabular}{|l|c|}
\hline Analysis of Knowledge Acquisition in Nepalese Telecom Industry & 0.741 \\
\hline Analysis of Information Input- Customer & 0.81 \\
\hline Analysis of Information Input- competitors & 0.741 \\
\hline Analysis of Information Input- Financial & 0.725 \\
\hline Analysis of Information Input-Employee & 0.811 \\
\hline Analysis of Information Input - Technology & 0.782 \\
\hline
\end{tabular}

\section{Analysis of Knowledge Acquisition in Nepalese Telecom Industry \\ Knowledge Acquisition}

The first constructed measure was Knowledge acquisition in this study, which was an index, based on seventeen knowledge acquisition (KA) related questions with five factors from the employees' survey. Five factors were customers, competitors, financial, employee and technology as information inputs.

Table 4 Analysis of Knowledge Acquisition in Nepalese Telecom Industry

\begin{tabular}{|l|c|c|c|}
\hline \multicolumn{1}{|c|}{ Definition } & Mean & Std & Alpha \\
\hline Knowledge Acquisition & 3.77 & & \\
\hline Information input- customers & 3.65 & 0.46 & \\
\hline Information input- competitors & 3.74 & 0.67 & \\
\hline Information input- financial & 4.13 & 0.49 & \\
\hline Information input- employee & 3.60 & 0.57 & \\
\hline Information input- technology & 3.71 & 0.75 & \\
\hline
\end{tabular}


The above table expresses the KM practice on knowledge acquisition in Nepalese Telecom industry, which shows 3.77 composite mean values for the KA variable. Among the factors that designed for knowledge acquisition, information input-financial scores highest mean 4.13, with standard deviation 0.49 which is more than average. Similarly information input- employee has less mean score with 3.60. It suggests that information input through employee is poor in comparison to others in Nepalese telecom industry.

\section{Knowledge Management Practices in Nepal telecom and Ncell}

The respondents from Nepal telecom accounted 61 and Ncell respondents are 24 as discussed below. Following table shows the mean differences in term of Analysis of Variance along with the descriptive statistics including mean and standard deviation of these two types of sample.

Table 5 Analysis of Variances of KM Practices in Nepal telecom and Ncell

\begin{tabular}{|c|l|c|c|c|c|c|}
\hline Factors & \multicolumn{1}{|c|}{ Organizations } & N & Mean & Std. Deviation & F & Sig \\
\hline \multirow{3}{*}{ Acquisition } & Nepal Telecom & 61 & 3.90 & 0.38 & & \\
& Ncell & 24 & 3.44 & 0.26 & \multirow{3}{*}{5.405} & 0.000 \\
& Total & 85 & 3.77 & 0.40 & \\
\hline
\end{tabular}

Table 5 shows that Nepal telecom has higher mean value in acquisition (mean=3.90), This means Nepal telecom appeared good in Knowledge Acquisition practices than the Ncell.

\section{Knowledge Acquisition (KA) Practices in Nepal telecom and Ncell.}

In total number of participants, respondents from Nepal telecom accounted 61 and respondents from Ncell. The five factors i.e. Information input-customer, competitors, financial, employees, and technology are used to measure the knowledge acquisition practices in Nepalese telecom industry.

Table 6 Analysis of Variances of Knowledge Acquisition (KA) factors in Nepal telecom and Ncell

\begin{tabular}{|l|l|c|c|c|c|c|}
\hline Factors & Organizations & $\mathrm{N}$ & Mean & Std. Deviation & $\mathrm{F}$ & Sig(p value) \\
\hline Information & Nepal telecom & 61 & 3.74 & 0.45 & & \\
Input- & Ncell & 24 & 3.44 & 0.43 & 7.68 & 0.007 \\
customers & Total & 85 & 3.65 & 0.46 & & \\
\hline \multirow{5}{*}{ Competitors } & Nepal telecom & 61 & 3.90 & 0.64 & & \\
& Ncell & 24 & 3.33 & 0.54 & \multirow{2}{*}{0.807} & 0.000 \\
& Total & 85 & 3.74 & 0.67 & & \\
\hline \multirow{5}{*}{ Financial } & Nepal telecom & 61 & 4.27 & 0.45 & & \\
& Ncell & 24 & 3.77 & 0.39 & \multirow{2}{*}{0.000} \\
\hline \multirow{5}{*}{ Employees } & Total & 85 & 4.13 & 0.49 & & \\
& Nepal telecom & 61 & 3.72 & 0.58 & & \\
& Ncell & 24 & 3.29 & 0.43 & 10.621 & 0.002 \\
\hline \multirow{3}{*}{ Technology } & Total & 85 & 3.60 & 0.57 & & \\
& Nepal telecom & 61 & 3.91 & 0.70 & & \multirow{2}{*}{0.000} \\
\hline
\end{tabular}

The table shows the five factors of knowledge acquisition practices in Nepal telecom and Ncell of $\sim 126 \sim$ 
Vol. 4, No. 1

Nepal. It shows the fact that Nepal telecom better practice in the factors of knowledge acquisition practice. It can be concluded that Nepalese telecom industry hold different level of practices of KA.

\section{Correlation among the factors of Study Variables}

Table 7 Correlation among Knowledge Acquisition Factors

\begin{tabular}{|l|l|c|c|c|c|c|}
\hline & & & \multicolumn{2}{|c|}{ Correlation Matrix } & & \\
\hline SN & Variables & Customer & Competitor & financial & employee & technology \\
\hline 1 & Customer & 1 & & & & \\
\hline 2 & Competitor & 0.194 & 1 & & & \\
\hline 3 & Financial & $.399^{* *}$ & $.548^{* *}$ & 1 & & \\
\hline 4 & Employee & $.355^{* *}$ & $.547^{* *}$ & $.681^{* *}$ & 1 & \\
\hline 5 & Technology & 0.147 & $.644^{* *}$ & $.375^{* *}$ & $.506^{* *}$ & 1 \\
\hline
\end{tabular}

**Correlation is significant at the 0.01 level (2-tailed).

The correlation amongst all the factors of knowledge acquisition are positively correlated each other's. Similarly the factors of the variables of KM practices are positively correlated each other. Only the customer information input factor seems not sufficiently correlated with the information input-technology and information input-competitors. The results state that there is positive relationship between the factors of knowledge management practices of Nepalese telecom industry.

\section{Major Findings of the Study}

The results of analysis of this study can be stated as follows;

- $\quad$ KM practice on the knowledge acquisition in Nepalese telecom sector organizations shows generally average level of status. Among the factors information input- employee has less mean score and information input-financial has high mean score than the others factors.

- The overall practices of responsive to competitors in Nepalese telecom industry were found in average level. Nepalese telecom industry are quick to decide how to competitors' initiatives.

- Employees of Nepal telecom has rated higher mean value in the KM practices i.e. knowledge acquisition. This means Nepal telecom appeared good in KM practices than Ncell.

\section{Conclusions}

KM practice on the knowledge acquisition in Nepalese telecom sector organizations shows generally average level of status. Among the factors that designed for knowledge acquisition, information inputemployee has less mean score and information input-financial has high mean score than the others factors. In case of Information input- competitors, Nepalese telecom industry analyze the financial contribution of their products or services. They know who their most profitable customers are. Information inputtechnology as knowledge acquisition factor that there is still need of improving in keeping up to data with technological developments that could affect their business. Employees of Nepal telecom has rated higher mean value in the KM practices i.e. knowledge acquisition, which means Nepal telecom appeared good in KM practices than Ncell. The results also shows significant differences between Nepal telecom and Ncell in term of the knowledge acquisition. When we observe in Competitors, Financial, Employees, Technology factors, the data structure shows same statistical results having higher score in Nepal telecom. It means Nepal telecom has better KA practices. Correlation matrix was computed to assess the extent or degree of relationship in between the factors or the research variables. 


\section{References}

Al-Athari, A., \& Zairi, M. (2001). Building Benchmarking Competence through Knowledge Management Capability: An empirical study of the Kuwaiti context, ' Benchmarking: An International Journal, $8(1), 70-80$.

Alavi \& Leider Sveiby (2001). The Adoption of Knowledge Management Systems in Small Firms. Electronic Journal of Knowledge Management Volume 8 Issue 1, 109

Antonelli, C. (1999). The evolution of the industrial organization of the production of knowledge. Cambridge Journal of Economics, Vol. 23, 243-60.

Capon, N., Farley, J.U., Lehmann, D.R. \& Hulbert, J.M. (1992). Profiles of product innovators among large US manufacturers. Management Science, Vol. 38 No. 2, 157-68.

Carneiro, A. (2000). How does knowledge management influence innovation and competitiveness? Journal of Knowledge Management, Vol. 4 No. 2, 87-98.

Chase, R.L. (1997). The knowledge-based organization: An international survey. Journal of Knowledge Management, 1(1), 38 - 49.

Connell, N.A.D., Klein, J. H. \& Powell, P.L., (2003). It's Tacit Knowledge but not as We Know it: Redirecting the Search for Knowledge. Journal of the Operation Research Society, 54, 140-152.

Connor, K.R. and Prahalad, C.K. (1996). A resource-based theory of the firm: knowledge versus opportunism. Organization Science, Vol. 7 No. 5, 477-501.

Darroch, J. (2003). Developing a measure of knowledge management behaviours and practices. Journal of Knowledge Management, Vol. 7 No. 5, 41-54.

Dove, R. (1999). Knowledge management, response ability, and the agile enterprise. Journal of Knowledge Management, Vol. 3 No. 1, 18-35.

Grant, R. M (2001). Prospering in dynamically-competitive environments: Organizational capability as knowledge integration. Organization Science (7:4), 1996a, 375-387

Hall, R. (1993). A framework linking intangible resources and capabilities to sustainable competitive advantage. Strategic Management Journal, Vol. 14, 607-18.

Kinney, T. (1998). Knowledge management, intellectual capital and adult learning, Adult Learning. 10 (2), $2-5$

Kohli, A.K., Jaworski, B.J. \& Kumar, A. (1993). MARKOR: a measure of market orientation. Journal of Marketing Research, Vol. 30, November, 467-77

Liebowitz, J. and Beckman, (1998). Knowledge Organizations: What Every Manager Should Know, St Lucie Press, New York, NY.

Nonaka \& Takeuchi, (1995). Nonaka, I., Takeuchi, H. (1995). The Knowledge-creating Company: How Japanese Companies Create the Dynamics of Innovation, Oxford University Press, New York, NY and Oxford.

Nonaka, I. (1994). A dynamic theory of organizational knowledge creation. Organization Science, Vol. 5, 14-37

Nonaka, I., Toyama, R., Byosiere, (2001). Emergence of 'Ba'. A conceptual framework for the continuous and self-transcending process of knowledge process".

Polanyi, M. (1967). The Tacit Dimension, Doubleday Anchor. New York, NY. 127-52.

Rafeeq, M., Nizamuddin, F., Asma, S, Ahmed, Z. Ali, \& Md. Afsar (2014). Knowledge management: competent employees are the only change agents of imperative organizational excellence. International Journal of Application or Innovation in Engineering \& Management, 3(11), 392-399. 
Vol. 4, No. 1

Sveiby, K.E. (1997). The New Organizational Wealth: Managing and Measuring Knowledge-Based Assets. New York: Barret-Koehler.

Syed-Ikhsan, S.O. and Rowland, F. (2004). Knowledge management in a public organization: A study on the relationship between organizational elements and the performance of knowledge transfer. Journal of Knowledge Management, Vol. 8 No. 2, 95-111

Teece, D.J. (1998). Capturing value from knowledge assets: the new economy, markets for know-how and intangible assets. California Management Review, Vol. 40 No. 3, 55-79.

Wiig, K.M. (1997). Knowledge management: an introduction and perspective. Journal of Knowledge Management, Vol. 1 No. 1, 6-14.

Wiig, K.M. (2000). Knowledge management foundations. Schema Press. Arlington. 